\title{
PERENCANAAN PERKERASAN JALAN RAYA CARIU KM BDG 79 - KM BDG 81 MENGGUNAKAN METODE PERENCANAAN PERKERASAN JALAN BETON SEMEN PD T-14-2003
}

\author{
${ }^{1}$ Fatchur Rochman, ${ }^{2}$ Mochammad Ichwan Nur Effendie, ${ }^{3}$ Yuda Indra Permana \\ Program Studi Teknik Sipil Fakultas Teknik Universitas Suryakancana \\ fatchurFT@unsur.ac.id, ichwan.one@gmail.com, yudaindrapermana88@gmail.com
}

\begin{abstract}
Abstrak
Seiring dengan perkembangan kebutuhan manusia, maka semakin banyak barang dan kebutuhan yang harus di distribusikan dari suatu daerah ke daerah lainnya, para penyedia jasa angkutan barang biasanya mengangkut barang melebihi kapasitas yang diizinkan untuk kendaraan bias melewati jalan tertentu, sehingga struktur perkerasan jalan semakin mudah rusak.

Kerusakan perkerasan jalan ini terjadi pula pada ruas Jalan Raya Cariu KM. BDG $79-$ KM. BDG 81, kerusakan terjadi pada struktur perkerasan kaku (rigid pavement) eksisting tanpa menggunakan tulangan. Kerusakan perkerasan ini dikarenakan kelebihan beban kendaraan yang dapat mengakibatkan kecelakaan. Kerusakan struktur perkerasan kaku tanpa tulangan ini akan dibandingkan dengan struktur perkerasan kaku dengan tulangan berdasarkan standar Pd T-14-2003.

Dari nilai CBR tanah dasar tersebut diperoleh nilai CBR efektif sebesar 28\%, Tebal pelat beton yang direncanakan setebal $30 \mathrm{~cm}$, dengan jenis dan tebal pondasi bawah adalah campuran beton kurus setebal $125 \mathrm{~mm}$. Penulangan pelat yang digunakan (dalam kasus ini digunkan pelat beton bersambung dengan tulangan) adalah Tulangan diameter $8 \mathrm{~mm}$ dengan jarak $150 \mathrm{~mm}$ untuk tulangan memanjang, dan, Tulangan diameter $8 \mathrm{~mm}$ dengan jarak $150 \mathrm{~mm}$ untuk tulangan melintang.Nilai jarak tulangan tersebut diambil berdasarkan luas tulangan minimum (As minimum).
\end{abstract}

Kata kunci : Perkerasan Jalan,Perkerasan Kaku,Perkerasan Lentur, CBR.

\section{PENDAHULUAN}

Seiring dengan perkembangan kebutuhan manusia, maka semakin banyak barang dan kebutuhan yang harus di distribusikan dari suatu daerah ke daerah lainnya. Para penyedia jasa angkutan barang biasanya mengangkut barang melebihi kapasitas yang diizinkan untuk kendaraan bisa melewati jalan tertentu, sehingga struktur perkerasan jalan semakin mudah rusak. Salah atunya adalah Jalan Raya Cariu KM. 79-81. Struktur perkerasan yang digunakan sudah menggunakan jenis perkerasan kaku (rigid pavement) tanpa menggunakan tulangan namun masih saja terjadi kerusakan pada lapisan pekerasan yang diakibatkan oleh kelebihan beban kendaraan yang sering mengakibatkan kecelakaan lalu lintas.

Apabila kerusakan jalan ini tetap dibiarkan, maka akan semakin banyak kecelakaan lalu lintas yang merenggut banyak korban jiwa dan menimbulkan ketidaknyamanan pengendara yang melewatui jalan tersebut. Alternatif untuk mengatasi kerusakan jalan ini adalah dengan menambahkan lapisan tambah (overlay) menggunakan aspal beton atau dalam perencanaan awal perkerasan beton menggunakan tulangan. Selain melakukan evaluasi dari segi struktur perkerasan jalan.

\section{TINJAUAN PUSTAKA}

Perkerasan jalan raya yang menggunakan konstruksi beton semen sebagai konstruksi perkerasannya atau lebih dikenal sebagai perkerasan kaku umumnya terdiri dari satu lapis konstruksi yang dibangun di atas lapisan tanah dasar (sub grade) atau di atas lapisan pondasi (base/subbase course) apabila diperlukan. Tegangan yang dihasilkan oleh lalu lintas yang melintasi jalan tersebut langsung ditahan oleh struktur perkerasan dan mendistribusikannya ke seluruh permukaan beton.

\section{a. Perkerasan Lentur}

Konstruksi perkerasan lentur jalan raya terdiri dari lapisan-lapisan yang diletakan di atas tanah dasar yang telah dipadatkan. Lapisan-lapisan tersebut berfungsi untuk menerima beban lalu-lintas dan menyebarkannya ke lapisan di bawahnya. 


\section{Lapisan Permukaan (Surface Course)}

Lapisan permukaan merupakan lapisan yang terletak paling atas dan terjadi kontak langsung dengan roda kendaraan. Fungsi lapisan permukaan antara lain adalah :

a. Lapis perkerasan penahan beban roda, lapisan mempunyai stabilitas tinggi untuk menahan beban roda selama masa pelayanan.

b. Lapis kedap air, sehingga air hujan yang jatuh di atas perkerasan jalan tidak meresap ke lapisan di bawahnya dan melemahakan lapisanlapisan tersebut.

c. Lapisan aus (wearing course), lapisan yang langsung menerima gesekan akibat rem kendaraan, sehingga mudah menjadi aus.

d. Lapis yang menyebarkan beban ke lapisan bawah, sehingga dapat dipikul oleh lapisan lain yang mempunyai daya dukung yang lebih jelek. Untuk dapat memenuhi fungsi-fungsi tersebut, pada umumnya lapisan permukaan dibuat dengan menggunakan bahan pengikat aspal, sehingga menghasilkan lapisan yang kedap air dengan stabilitas yang tinggi dan daya tahan yang lama.

\section{Lapisan Pondasi Atas (Base Course)}

Lapisan ini adalah lapisan yang terletak diantara lapisan pondasi bawah dan lapisan permukaan. Fungsi dari lapisan pondasi atas antara lain adalah:

a. Bagian perkerasan yang menahan gaya lintang dari beban roda dan menyebarkan beban ke lapisan di bawahnya.

b. Lapisan peresapan untuk lapisan pondasi bawah.

c. Bantalan terhadap lapisan permukaan

Material yang akan digunakan untuk lapis pondasi atas adalah material yang cukup kuat. Untuk lapis pondasi atas tanpa bahan pengikat, umumnya menggunakan material dengan $\mathrm{CBR}>50 \%$ dan Indeks Plastis (IP) $<4 \%$. Bahan-bahan alam seperti: batu pecah, kerikil pecah, stabilisasi tanah dengan semen dan kapur dapat digunakan juga sebagai lapisan pondasi atas.

\section{Lapisan Pondasi Bawah (Subbase Course)}

Lapisan pondasi bawah adalah lapisan perkerasan yang terletak antara lapis pondasi atas dan tanah dasar. Lapisan pondasi bawah ini berfungsi sebagai

a. Bagian dari konstruksi perkerasan untuk menyebarkan beban roda ke tanah dasar. Lapisan ini harus cukup kuat, mempunyai CBR $20 \%$ dan Indeks Plastis $\leq 10 \%$.

b. Effesiensi penggunaan material. Material pondasi bawah relative murah dibandingkan dengan lapisan perkerasan di atasnya. c. Mengurangi tebal lapisan di atasnya yang lebih mahal.

d. Lapis peresapan, agar air tanah tidak berkumpul di pondasi.

e. Lapisan pertama, agar pekerjaan dapat berjalan lancar. Hal ini sehubungan dengan kondisi lapangan yang memaksa harus segera menutup tanah dasar dari pengaruh cuaca atau lemahnya daya dukung tanah dasar menahan roda-roda alat besar.

f. Lapisan untuk mencegah partikel-partikel halus dari tanah dasar naik ke lapis pondasi atas, untuk itu lapisan pondasi bawah haruslah memenuhi syarat filter.

\section{Lapisan Tanah Dasar (Subgrade)}

Lapisan tanah dasar adalah lapian tanah setebal 50$100 \mathrm{~cm}$ dimana akan diletakkan lapisan pondasi bawah. Lapisan tanah dasar dapat berupa tanah asli yang dipadatkan jika tanah aslinya baik, atau tanah yang didatangkan dari tempat lain dan dipadatkan, atau tanah yang di stabilisasi dengan kapur atau bahan lainnya. Pemadatan yang baik diperoleh jika dilakukan pada kadar air optimum dan diusahakan kadar air tersebut konstan selama umur rencana. Hal ini dapat dicapai dengan perlengkapan drainase yang memenuhi syarat.

Sebelum diletakkan lapisan-lapisan lainnya, tanah dasar dipadatkan terlebih dahulu sehingga tercapai kestabilan yang tinggi terhadap perubahan volume. Kekuatan dan keawetan konstruksi perkerasan jalan sangat ditentukan oleh sifat- sifat daya dukung tanah dasar. Masalah-masalah yang sering ditemui yang berhubungan dengan tanah dasar adalah :

a. Perubahan bentuk tetap dari jenis tanah tertentu akibat beban lalu-lintas. Perubahan bentuk yang besar akan mengakibatkan jalan tersebut rusak. Tanah-tanah dengan plastisitas tinggi cenderung untuk mengalami hal tersebut. Lapisan-lapisan tanah lunak yang terdapat di bawah tanah dasar harus diperhatikan. Daya dukung tanah dasar yang ditunjukkan oleh nilai CBRnya dapat merupakan indikasi dari perubahan bentuk yang terjadi.

b. Sifat mengembang dan menyusut dari tanah tertentu akibat perubahan kadar air. Hal ini dapat dikurangi dengan memadatkan tanah pada kadar air optimum, sehingga mencapai kepadatan tertentu sehingga perubahan volume yang mungkin terjadi dapat dikurangi. Kondisi drainase yang baik dapat menjaga kemungkinan berubahnya kadar air pada lapisan tanah dasar. 
c. Daya dukung tanah dasar yang tidak merata pada daerah dengan macam tanah yang sangat berbeda. Penelitian yang seksama atas jenis dan sifat tanah dasar sepanjang jalan dapat mengurangi akibat tidak meratanta daya dukung tanah dasar. Perencanaan tebal perkerasan dapat dibuat berbeda-beda dengan membagi jalan menjadi segmen-segmen berdasarkan sifat tanah yang berlainan.

d. Daya yang tidak merata akibat pelaksanaan yang kurang baik. Hal ini akan lebih jelek pada tanah dasar dari jenis tanah berbutir kasar dengan adanya tambahan pemadatan akibat pembebanan lalu lintas ataupun akibat berat tanah itu sendiri (pada tanah dasar timbunan). Hal ini dapat diatasi dengan melakukan pengawasan yang baik pada saat pelaksanaan pekerjaan tanah dasar.

e. Perbedaan penururnan (differential settlement) akibat terdapatnya lapisan-lapisan tanah lunaj di bawah tanah dasar akan mengakibatkan terjadinya perubahan bentuk tetap. Hal ini dapat diatasi dengan melakukan penyelidikan tanah dengan teliti. Pemeriksaan dengan menggunakan alat bor dapat memberikan gambaran yang jelas tentang lapisan tanajh di bawah lapisan tanah dasar.

f. Kondisi geologis dari lokasi jalan perlu dipelajari dengan teliti, jika ada kemungkinan lokasi jalan berada pada daerah patahan dan sebagainya.

\section{b. Perkerasan Kaku}

Perkerasan kaku atau perkerasan beton semen adalah struktur yang terdiri atas pelat beton semen yang bersambung (tidak menerus) tanpa atau dengan tulangan, atau menerus dengan tulangan, terletak di atas lapis pondasi bawah atau tanah dasar, tanpa atau dengan lapis permukaan beraspal. Struktur perkerasan beton semen secara tipikal sebagaimana terlihat pada Gambar 1 di bawah ini.

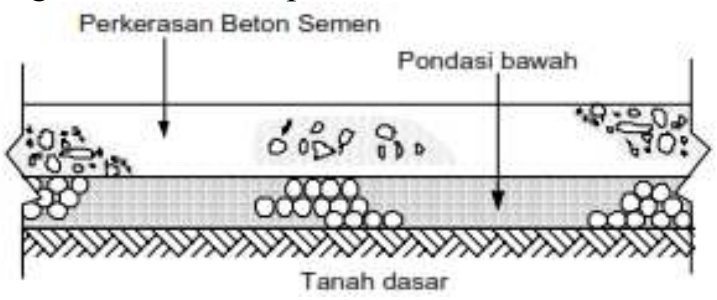

Gambar 1. Tipikal struktur perkerasan beton semen

Sumber : Perencanaan Perkerasan Jalan Beton Semen Pd T14-2003
Pada perkerasan beton semen, daya dukung perkerasan terutama diperoleh dari pelat beton. Sifat, daya dukung dan keseragaman tanah dasar sangat mempengaruhi keawetan dan kekuatan perkerasan beton semen. Faktor-faktor yang perlu diperhatikan adalah kadar air pemadatan, kepadatan dan perubahan kadar air selama masa pelayanan.

Lapis pondasi bawah pada perkerasan beton semen adalah bukan merupakan bagian utama yang memikul beban, tetapi merupakan bagian yang berfungsi sebagai berikut :

a. Mengendalikan pengaruh kembang susut tanah dasar.

b. Mencegah intrusi dan pemompaan pada sambungan, retakan dan tepi-tepi pelat.

c. Memberikan dukungan yang mantap dan seragam pada pelat.

d. Sebagai perkerasan lantai kerja selama pelaksanaan.

Pelat beton semen mempunyai sifat yang cukup kaku serta dapat menyebarkan beban pada bidang yang luas dan menghasilkan tegangan yang rendah pada lapisan-lapisan di bawahnya. Bila perlu tingkat kenyamanan yang tinggi, permukaan perkerasan beton semen dapat dilapisi dengan lapis campuran beraspal setebal $5 \mathrm{~cm}$.

\section{METODOLOGI}

Metode penyelesaian masalah, tahapan dan data cara penyelesaian beserta data-data yang telah didapat oleh peneliti. Jalan Raya Cariu KM. 79-81 menggunakan perkerasan kaku, sehingga dalam evaluasi ini dilakukan perencanaan ulang pelat beton semen menggunakan standar PdT-14-2003. Dalam perencanaan perkerasan jalan yang baru, digunakan data-data perencanaan seperti data lalu lintas, daya dukung tanah (CBR) dan data geometrik jalan eksisting berdasarkan peninjauan langsung di lapangan. Karena terbatasnya data-data yang berhubungan dengan evaluasi dan perencanaan ulang jalan ini, maka digunakan asumsi perencanaan yang dianggap sama dengan perencanaan jalan ini sebelumnya. 


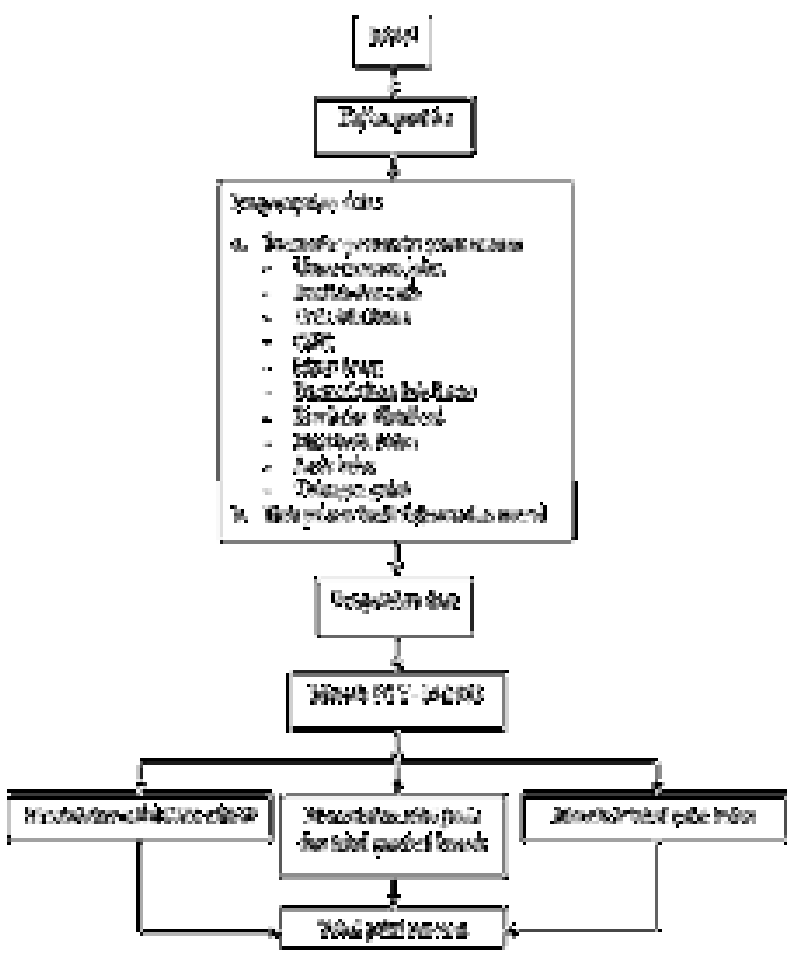

Gambar 2. Diagram Alir Metodologi Penyelesaian Penelitian

Data yang diperlukan dalam perencanaan struktur perkerasan kaku adalah data primer dan data sekunder. Dikarenakan terbatasnya data-data perencanaan, seperti data CBR tanah dasar, maka digunakan asumsi CBR tanah perencanaan teknis Jalan Cibadak - Cikidang - Pelabuhan Ratu untuk evaluasi ruas jalan yang dikaji. Pengumpulan data sekunder dilakukan dengan mendatangi instansi terkait, untuk mendapatkan data-data mengenai parameter-parameter struktur perkerasan kaku. Data-data sekunder tersebut antara lain :

a. Data lalu lintas (lampiran)

b. Nilai CBR (berdasarkan rekomendasi dosen pembimbing, dengan asumsi nilai CBR jalan yang dievaluasi memiliki nilai yang sama dengan CBR tanah dasar perencanaan teknis Jalan Cibadak - Cikidang - Pelabuhan Ratu)

c. Curah Hujan

Selain data-data sekunder yang telah didapatkan dari beberapa instansi yang terkait, dilakukan juga survey langsung ke lapangan untuk mendapatkan data primer. Data primer yang didapatkan dari survey langsung ke lapangan antara lain adalah :

a. Tebal pelat eksisting

b. Lebar jalan eksisting

c. Kerusakan jalan yang terjadi

Setelah data-data primer dan sekunder didapatkan, maka dilakukan studi literatur untuk mencari data atau keterangan lain yang dibutuhkan dari buku-buku atau teori dari materi-materi perkuliahan yang telah diberikan. Untuk mendapatkan masukan pemecahan masalah, dilakukan diskusi antar mahasiswa dan dosen lainnya yang berkompeten dalam bidang perencanaan jalan.

\section{Pengumpulan Data Primer}

Pada tahapan ini, penulis melakukan pengumpulan data yang diperoleh dari survey dan pengamatan langsung di lapangan. Beberapa ruang lingkup yang akan dibahas antara lain :

- Hasil pengamatan sendiri mengenai jenis kendaraan yang melewati ruas jalan tersebut dan juga material yang diangkut oleh kendaraan tersebut.

- Foto visual mengenai geometrik jalan yang ada.

- Foto visual mengenai kerusakan perkerasan yang terjadi.

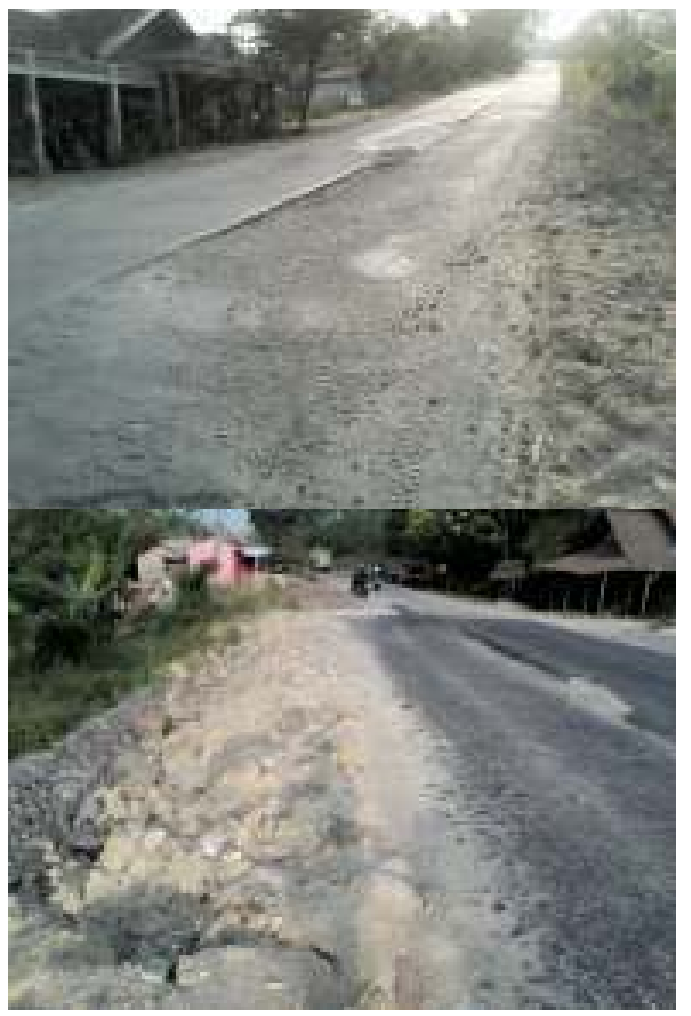

Gambar 3 Kondisi jalan di lokasi penelitian Sumber : dokumentasi pribadi

\section{Pengumpulan Data Sekunder}

Data sekunder adalah data penelitian yang diperoleh peneliti secara tidak langsung melalui media perantara (diperoleh dan dicatat oleh pihak lain). Data sekunder umumnya berupa bukti, catatan atau laporan historis yang terlah tersusun dalam arsip (data dokumentasi) yang dipublikasikan dan yang tidak dipublikasikan. 
Berikut ini adalah data-data sekunder yang didapat dari beberapa instansi yang berkaitan dengan perencanaan jalan tersebut, antara lain :

- Data Lintas Harian Rata-rata (LHR) yang melintas ruas Jalan Raya Cariu KM BDG $79+$ $0.00-81 \pm 0.00$ yang didapatkan dari Dinas PU Bina Marga Provinsi Jawa Barat.

- Peta kontur ruas Jalan Raya Cariu KM BDG 79 $\pm 0.00-81 \pm 0.00$ yang didapat dari Badan Informasi Geografi (BIG) yang sebelumnya bernama BAKOSURTANAL (Badan Koordinator Survey dan Pemetaan Nasional).

- Data daya dukung tanah berupa data CBR (California Bearing Ratio) yang didapat dari perencanaan teknis Jalan Raya Cariu KM BDG $79 \pm 0.00-81 \pm 0.00$.

\section{PEMBAHASAN}

\section{Pengumpulan Data Penelitian}

\section{a. Pengumpulan data volume kendaraan}

Data lalu lintas suatu jalan atau potongan jalan pada umumnya dapat dikumpulkan dari badan-badan yang biasanya melakukan survey lalu lintas, seperti Departemen Perhubungan dan juga Dinas Bina Marga atau bisa juga dengan melakukan survey primer, untuk mengetahui seperti apa dan berapa jumlah kendaraan yang melalu segmen jalan yang akan ditinjau.

Survey lalu lintas dalam hal ini dilakukan biasanya selama sehari penuh atau 24 jam tanpa henti, namun dalam hal ini penulis memilih menggunakan data yang telah didapatkan dari sumber yang dapat dipercaya untuk mengurangi resiko adanya kesalahan perhitungan pada jumlah kendaraan yang melewati jalan tersebut. Dalam evaluasi jalan ini, penulis menggunakan data yang didapatkan dari sumber yang dapat dipercaya untuk mengurangi resiko adanya kesalahan hitungan jumlah kendaraan yang melewati segmen jalan tersebut. Data yang digunakan penulis didapat dari Dinas
Pekerjaan Umum Bina Marga Provinsi Jawa Barat (Bandung) dengan harapan data yang digunakan lebih akurat dibandingkan dengan melakukan survey sendiri, karena data yang didapatkan berasal dari dinas yang credible.

Arus kendaraan yang melewati ruas Jalan Raya Cariu KM BDG $79+000-81+000$ bervariasi mulai dari jenis kendaraan dan komposisinya. Jenis kendaraan dikelompokan menjadi kendaraan ringan (LV), kendaraan berat menengah (MHV), truk besar (LT), bis besar (LB) dan sepeda motor (MC).

1. Kendaraan ringan / low vehicle

Kendaraan bermotor roda empat, dengan dua gandar berjarak 2,0 - 3,0 meter (termasuk kendaraan penumpang, oplet, mikro bus, pick up, sesuai sistem klasifikasi Bina Marga).

2. Kendaraan berat menengah / medium high vehicle

Kendaraan bermotor beroda empat, dengan dua gandar berjarak 3,5-5,0 meter (termasuk bus kecil, truk dua as dengan enam roda, pick up dan truk sesuai sistem klasifikasi Bina Marga).

3. Truk besar/ high truck

Truk tiga gandar dan truk kombinasi dengan jarak gandar (gandar pertama ke gandar kedua) $<3,5$ meter (sesuai dengan sistem klasifikasi Bina Marga).

4. Bus besar / large bus

Bus dengan dua atau tiga gandar dengan jarak as 5,0 $-6,0$ meter. (sesuai dengan sistem klasifikasi Bina Marga)

5. Sepeda motor / motor cycle

Sepeda modtor dengan dua atau tiga roda (meliputi sepeda motor dan kendaraan beroda tiga sesua sistem klasifikasi Bina Marga).

Tabel 1 Data LHR (Lalu Lintas Harian Rata-rata)

\begin{tabular}{|c|c|c|c|c|c|c|c|c|c|c|c|c|}
\hline & $\begin{array}{c}\text { Sepeda } \\
\text { motor, } \\
\text { Sekuter } \\
\text { dan } \\
\text { Kendaraa } \\
\text { n roda } \\
\text { tiga }\end{array}$ & $\begin{array}{c}\text { Sedan, } \\
\text { Jeep } \\
\text { dan } \\
\text { Statio } \\
\text { n } \\
\text { Wago } \\
\text { n }\end{array}$ & $\begin{array}{l}\text { Opelet, } \\
\text { Pick up } \\
\text { opelet, } \\
\text { Suburba } \\
\text { n Combi } \\
\text { dan Mini } \\
\text { bus }\end{array}$ & $\begin{array}{c}\text { Pick up, } \\
\text { Micro } \\
\text { truk dan } \\
\text { Mobil } \\
\text { hantara } \\
n\end{array}$ & $\begin{array}{l}\text { Bus } \\
\text { keci } \\
1\end{array}$ & $\begin{array}{c}\text { Bus } \\
\text { besa } \\
r\end{array}$ & $\begin{array}{c}\text { Truk } \\
2 \\
\text { sumb } \\
u \\
\text { (Smal } \\
1 \\
\text { Truck } \\
\text { ) } \\
\end{array}$ & $\begin{array}{c}\text { Truck } \\
2 \\
\text { sumb } \\
\text { u } \\
\text { (large } \\
\text { Truck } \\
\quad \text { ) }\end{array}$ & $\begin{array}{c}\text { Truk } \\
3 \\
\text { sumb } \\
\mathrm{u}\end{array}$ & $\begin{array}{c}\text { Truk } \\
\text { ganden } \\
\mathrm{g}\end{array}$ & $\begin{array}{c}\text { Truk } \\
\text { semi } \\
\text { traile } \\
\text { r }\end{array}$ & $\begin{array}{c}\text { Kendaraa } \\
\text { n tidak } \\
\text { bermotor }\end{array}$ \\
\hline Golongan & 1 & 2 & 3 & 4 & $5 \mathrm{a}$ & $5 b$ & $6 a$ & $6 \mathrm{~b}$ & $7 \mathrm{a}$ & $7 \mathrm{~b}$ & $7 \mathrm{c}$ & 8 \\
\hline $\begin{array}{c}\text { Banyak } \\
\text { Kendaraan }\end{array}$ & 4680 & 4172 & 2236 & 4626 & 102 & 57 & 1512 & 966 & 1004 & 72 & 88 & 65 \\
\hline
\end{tabular}

Sumber : Dinas Bina Marga Provinsi Jawa Barat 


\section{b. Pengumpulan data tanah dasar}

Tanah dasar merupakan hal yang terpenting dari perencanaan suatu konstruksi perkerasan jalan raya. Tanah dasar akan mempengaruhi tebal lapis perkerasan yang akan digunakan agar jalan dapat melayani lalu lintas selama umur rencana.

Tabel 2. Nilai CBR Penelitian

\begin{tabular}{cc}
\hline \multicolumn{2}{c}{ CBR Jalan Cariu } \\
\hline STA & CBR (\%) \\
\hline $79+000$ & 2.40 \\
\hline $79+100$ & 2.40 \\
\hline $79+200$ & 4.00 \\
\hline $79+300$ & 3.50 \\
\hline $79+400$ & 3.40 \\
\hline $79+500$ & 3.50 \\
\hline $79+600$ & 3.40 \\
\hline $79+700$ & 3.50 \\
\hline $79+800$ & 3.80 \\
\hline $79+900$ & 3.50 \\
\hline $80+000$ & 3.40 \\
\hline $81+100$ & 3.40 \\
\hline $81+200$ & 3.50 \\
\hline $81+300$ & 3.20 \\
\hline $81+400$ & 3.00 \\
\hline $81+500$ & 2.90 \\
\hline $81+600$ & 2.60 \\
\hline $81+700$ & 2.70 \\
\hline $81+800$ & 3.80 \\
\hline $81+900$ & 3.70 \\
\hline $82+000$ & 3.80 \\
\hline
\end{tabular}

Sumber : Data perencanaan Jalan Raya Cariu KM BDG $79 \pm 0.00-81 \pm 0.00$

\section{Pengolahan Data}

Pengolahan data ini dimaksudkan untuk mendapatkan hasil perencanaan struktur perkerasan kaku dengan metode $\mathrm{Pd}$ T -14-2003

a. Tahapan Perencanaan Metode Pd T-142003

1. Mengetahui dan menentukan nilai parameterparameter perencanaan yang akan digunakan dalam perhitungan, seperti :

a. Memilih kuat tarik lentur atau kuat tekan beton pada umur 28 hari (f'cf),

b. Menentukan jenis dan tebal pondasi bawah berdasarkan nilai CBR rencana dan perkiraan,

c. Menentukan nilai koefisien gesek, d. Memilih jenis bahu jalan, yaitu bahu beton atau bukan beton,

e. Memilih jenis sambungan untuk perkerasan kaku, yaitu bersambung tanpa ruji, bersambung dengan ruji, atau menerus dengan tulangan.

f. Mengetahui volume lalu lintas yang ada pada awal umur rencana,

g. Menentukan persentase pertumbuhan lalu lintas (i),

h. Menentukan umur rencana (UR),

i. Menentukan jumlah lajur dan jumlah arah rencana,

j. Menentukan koefisien distribusi (C) sesuai Tabel 4 Pd T-14-2003, hal 10 pada Lampiran I, yang merupakan hubungan dari jumlah lajur dan jumlah arah rencana yang telah ditentukan (nomor 1-j).

2. Analisis lalu lintas, dengan menghitung jumlah sumbu kendaraan niaga selama umur rencana (JSKN). Dalam melakukan oerhitungan JSKN, menggunakan parameter volume lalu lintas (nomor 1-g), nilai i, UR, C dan faktor pertumbuhan lalu lintas (R). Nilai $R$ tersebut didapatkan dari persamaan pada Bab II, hal. 34, sedangkan untuk menentukan nilai JSKN selama umur rencana didapatkan dari persamaan : JSKN $=$ JSKNH x $365 \times$ xR $\times$ C.

3. Perhitungan tebal pelat beton, dengan langkahlangkah sebagai berikut :

a. Sumber data beban berdasarkan hasil survai,

b. Menentukan faktor keamanan beban lalu lintas (FKB), (sesuai Tabel 4 Pd T-142003, hal. 12) pada Lampiran,

c. Menentukan nilai CBR efektif, yang diambil dari nilai CBR rencana (sesuai Gambar 3 Pd T-14-2003, hal. 8) pada Lampiran, yaitu merupakan hubungan antara nilai CBR rencana dan pondasi bawah yang telah ditentukan sebelumnya.

d. Taksir tebal pelat beton (taksiran awal dengan tebal tertentu, berdasarkan pengalaman atau menggunakan contoh yang tersedia atau dapat menggunakan Gambar 24 sampai dengan Gambar 31 (dalam Pd T-14-2003) pada Lampiran.

4. Menentukan tegangan ekivalen (TE) dan faktor erosi (FE) untuk STRT dari Tabel 8 atau Tabel 9 (Pd T-14-2003) pada Lampiran.

5. Menentukan faktor rasio tegangan (FRT) dengan membagi tegangan ekivalen (TE) oleh kuat tarik-lentur (f'cf). 
6. Untuk setiap rentang beban kelompoj sumbu tersebut, tentukan beban per roda dan kalikan dengan faktor keamanan beban (FKB) untuk menentukan beban rencana per roda. Jika beban rencana beban per roda $\geq 65 \mathrm{kN}$ (6,5 ton), anggap dan gunakan hasil nilai tersebut sebagai batas tertinggi pada Gambar 19 sampai Gambar 21 (Pd T-14-2003, hal. 26-28) pada Lampiran.

7. Dengan faktor rasio tegangan (FRT) dan beban rencana, tentukan jumlah repetisi ijin untuk fatik dari Gambar 19 (Pd T-14-2003) pada Lampiran, yang dimulai dari beban roda tertinggi dari jenis sumbu STRT tersebut.

8. Menghitung persentase dari repetisi fatik yang direncanakan terhadap jumlah repetisi ijin.

9. Dengan menggunakan faktor erosi (FE), dapat ditentukan jumlah repetisi ijin untuk erosi, dari Gambar 20 atau 21 (Pd T-14-2003) pada Lampiran.

10. Menghitung persentase dari repetisi erosi yang direncanakan terhadap jumlah repetisi ijin.

11. Mengulangi langkah nomor 7 sampai dengan 10 untuk setiap beban per roda pada sumbu tersebut samapi jumlah repetisi beban ijin yang terbaca pada Gambar 19 dan Gambar 20 atau Gambar 21 (Pd T-14-2003) pada Lampiran I yang masing-masing mencapai 10 juta dan 100 juta repetisi.

12. Menghitung jumlah total fatik dengan menjumlahkan perentase fatik dari setiap roda pada STRT tersebut. Dengan cara yang sama, hitung jumlah total erosi dari setiap beban roda pada STRT tersebut.
13. Mengulangi langkah nomor 4 sampai dengan langkah nomor 12 untuk setiap jenis kelompok sumbu lainnya.

14. Menghitung jumlah total kerusakan akibat fanik dan jumlah total kerusakan akibat erosi untuk seluruh jenis kelompok sumbu.

15. Mengulangi langkah nomor 3-d sampai dengan nomor 3-d sampai dengan langkah 14 hingga diperoleh ketebalan tertipis yang menghasilkan total kerusakan akibat fatik dan erosi $\leq 100 \%$. Tebal tersebut sebagai tebal pelat beton semen yang direncanakan.

\section{b. Menentukan Nilai CBR dan Daya Dukung Tanah (DDT)}

Data yang berkaitan dengan perencanaan Jalan Raya Cariu KM BDG $79+0.00-81+0.00$, data nilai CBR tersebut diperoleh dari Dinas Bina Marga Provinsi Jawa Barat diperoleh nilai CBR yang mewakili ruas Jalan Raya Cariu KM BDG $79 \pm$ $0.00-81 \pm 0.00$ sebesar $2,8 \%$.

\section{c. Analisis Lalu-lintas}

Berdasarkan data hasil survey volume kendaraan yang telah dilakukan oleh pihak Dinas Bina Marga Provinsi Jawa Barat dan di analisa di dapat hasil Perhitungan repitisi sumbu rencana disajikan di tabel 2.

Tabel 2 Perhitungan repetisi sumbu rencana

\begin{tabular}{lllllll}
\hline $\begin{array}{l}\text { Jenis } \\
\text { Sumbu }\end{array}$ & $\begin{array}{l}\text { Beban } \\
\text { (ton) }\end{array}$ & $\begin{array}{l}\text { Jumbah Sumbu } \\
(\mathrm{bh})\end{array}$ & $\begin{array}{l}\text { Proporsi } \\
\text { Beban }\end{array}$ & $\begin{array}{l}\text { Proporsi } \\
\text { Sumbu }\end{array}$ & $\begin{array}{l}\text { Lalu } \\
\text { Rencana }\end{array}$ & $\begin{array}{l}\text { Lintas } \\
\text { Repetisi yang } \\
\text { Terjadi }\end{array}$ \\
\hline$(1)$ & $(2)$ & $(3)$ & $(4)$ & $(5)$ & $(6)$ & $(7)=(4) \times(5) \times(6)$ \\
\hline & 6 & 1130 & 0.20 & 0.72 & 470630744.5 & 67770827.21 \\
\cline { 2 - 7 } & 5 & 1166 & 0.21 & 0.72 & 470630744.5 & 71159368.57 \\
\cline { 2 - 7 } STRT & 4 & 1619 & 0.29 & 0.72 & 470630744.5 & 98267699.45 \\
\cline { 2 - 7 } & 3 & 60 & 0.01 & 0.72 & 470630744.5 & 3388541.36 \\
\hline Total & 2 & 1619 & 0.29 & 0.72 & 470630744.5 & 98267699.45 \\
\hline STRG & 8 & 5594 & 1.00 & & & \\
\hline Total & 5 & 1014 & 0.94 & 0.14 & 470630744.5 & 61935005.98 \\
\hline STdRG & 14 & 60 & 0.06 & 0.14 & 470630744.5 & 3953298.25 \\
\hline Total & 1074 & 1.00 & & & \\
\hline Kumulatif Sumbu & 1130 & 1.00 & 0.14 & 470630744.5 & 65888304.23 \\
\hline
\end{tabular}




\section{d. Perhitungan Tebal dan Penulangan Pelat}

Setelah perhitungan repetisi sumbu rencana didapatkan, selanjutnya adalah perhitungan tebal pelat beton. Berikut ini data-data yang diperlukan dalam perhitungan tebal pelat beton :

- Sumber data beban : Hasil survey

- Jenis perkerasan : Perkerasan beton bersambung dengan tulangan

- Jenis bahu : Tanpa bahu beton

- Umur rencana : 20 Tahun

- JSKN $_{\text {rencana }} \quad: \quad 470.630 .744,5$ (tidak termasuk kendaraan ringan)

- Faktor keamanan beban : berdasarkan Tabel 4, "Perencanaan Perkerasan Jalan Beton Semen, Pd T-14-2003", diambil 1,1 untuk jalan kolektor.

- Kuat tarik lentur beton: $\mathrm{f}^{\prime}{ }_{\mathrm{cf}}$ untuk beton dengan $\mathrm{f}^{\prime} \mathrm{c}=375 \mathrm{~kg} / \mathrm{cm}^{2}$ dari rumus $\mathrm{f}_{\mathrm{cf}}=3,13 \times \mathrm{K} \mathrm{K}$ (fc') $)^{0,5}$ didapat $45 \mathrm{~kg} / \mathrm{cm}^{2}$ atau 4,5 MPa dengan nilai K 0,75 (agregat pecah).

- CBR tanah dasar : $2,8 \%$

- Jenis dan tebal pondasi : $125 \mathrm{~mm}$ campuran beton kurus, berdasarkan Gambar 2, "Perencanaan Perkerasan Jalan Beton Semen, Pd T-14-2003", untuk CBR tanah dasar 2,8\% dan JSKN 470.630.744,5.

- CBR efektif : 28\%, berdasarkan Gambar 3, "Perencanaan Perkerasan Jalan Beton Semen, Pd T-14-2003", untuk CBR tanah dasar 2,8\% dan lapis pondasi campuran beton kurus setebal $125 \mathrm{~mm}$.

- Tebal taksiran pelat: $30 \mathrm{~cm}$ (hasil trial and error beberapa tebal pelat beton).

- Perhitungan beban rencana per roda kendaraan : Beban per roda STdRG = berat sumbu STdRG / jumlah roda $x F_{K B}$

STdRG 14 ton $(140 \mathrm{kN})=140 \mathrm{kN} / 8 \times 1,1=$ $19,25 \mathrm{kN} /$ roda

Setelah perhitungan beban rencana per roda kendaraan dilakukan, langkah selanjutnya adalah mencari Tegangan Ekivalen (TE) dan Faktor Erosi (FE) menggunakan Tabel 8, "Perencanaan Perkerasan Jalan Beton Semen, Pd T-14-2003". Nilai Tegangan Ekivalen (TE) dan Faktor Erosi (FE) dicari untuk masing-masing jenis sumbu, berdasarkan nilai CBR efektif dan untuk Faktor Erosi (FE) diambil untuk dengan ruji. Dikarenakan nilai CBR efektif $28 \%$ tidak tercantum, dilakukan interpolasi linear untuk nilai Faktor Erosi (FE) dan Tegangan Ekivalen (TE) berdasarkan nilai CBR efektif $25 \%$ dan $35 \%$.

Berdasarkan hasil interpolasi linear yang telah dilakukan, didapatkan nilai-nilai Faktor Erosi (FE) dan Tegangan Ekivalen (TE) sebagai berikut :
- Sumbu tunggal roda tunggal, didapat nilai $\mathrm{FE}=$ 1,677 dan nilai $\mathrm{TE}=0,554$.

- Sumbu tunggal roda ganda, didapat nilai $\mathrm{FE}=$ 2,287 dan nilai $\mathrm{TE}=0,888$.

- $\quad$ Sumbu tandem roda ganda, didapat nilai $\mathrm{FE}=$ 2,451 dan nilai $\mathrm{TE}=0,805$.

Berdasarkan nilai Tegangan Ekivalen (TE) dan kuat tarik lentur slab beton $\left(\mathrm{f}_{\mathrm{cf}}\right)$, dihasilkan Faktor Rasio Tegangan (FRT) sebagai berikut :

- Sumbu tunggal roda tunggal, didapat nilai FRT $=0,123$.

- Sumbu tunggal roda ganda, didapat nilai FRT = 0,197 .

- Sumbu tandem roda ganda, diperoleh nilai FRT $=0,179$.

Berdasarkan nilai Faktor Rasio Tegangan (FRT), Faktor Erosi (FE) dan beban per roda pada kelompok sumbu, dicari nilai repetisi ijin berdasarkan masing-masing beban per roda pada kelompok sumbu menggunakan Gambar 19 untuk analisis fatik dan Gambar 20 untuk analisis erosi Hasil penggunaan nomogram tersebut disajikan dalam bentuk tabel di bawah ini : 
Tabel 3. Analisa fatik dan erosi

\begin{tabular}{|c|c|c|c|c|c|c|c|c|}
\hline \multirow[b]{2}{*}{$\begin{array}{l}\text { Jenis } \\
\text { Sumb } \\
\text { u }\end{array}$} & \multirow[b]{2}{*}{$\begin{array}{l}\text { Beban } \\
\text { Sumbu } \\
(\mathrm{kN})\end{array}$} & \multirow[b]{2}{*}{$\begin{array}{l}\text { Beban Rencana } \\
\text { Per Roda }(\mathrm{kN})\end{array}$} & \multirow[b]{2}{*}{$\begin{array}{l}\text { Repetisi } \\
\text { yang } \\
\text { Terjadi }\end{array}$} & \multirow[b]{2}{*}{$\begin{array}{l}\text { Faktor } \\
\text { Tegangan dan } \\
\text { Erosi }\end{array}$} & \multicolumn{2}{|c|}{ Analisa Fatik } & \multicolumn{2}{|c|}{ Analisa Erosi } \\
\hline & & & & & $\begin{array}{l}\text { Repeti } \\
\text { si Ijin }\end{array}$ & $\begin{array}{l}\text { Persen } \\
\text { Rusak } \\
(\%)\end{array}$ & $\begin{array}{l}\text { Repeti } \\
\text { si Ijin }\end{array}$ & $\begin{array}{l}\text { Persen } \\
\text { Rusak } \\
(\%)\end{array}$ \\
\hline \multirow{5}{*}{ STRT } & 60 & 33.00 & $\begin{array}{l}67770827 . \\
21 \\
\end{array}$ & $\mathrm{FE}=1,677$ & TT & 0 & TT & 0 \\
\hline & 50 & 27.50 & $\begin{array}{l}71159368 . \\
57\end{array}$ & $\mathrm{TE}=0,554$ & TT & 0 & TT & 0 \\
\hline & 40 & 22.00 & $\begin{array}{l}98267699 . \\
45\end{array}$ & $\mathrm{FRT}=0,123$ & TT & 0 & TT & 0 \\
\hline & 30 & 16.50 & $\begin{array}{l}3388541.3 \\
6\end{array}$ & & TT & 0 & TT & 0 \\
\hline & 20 & 11.00 & $\begin{array}{l}98267699 . \\
45\end{array}$ & & TT & 0 & TT & 0 \\
\hline \multirow{2}{*}{ STRG } & 80 & 22 & $\begin{array}{l}61935005 . \\
98\end{array}$ & $\mathrm{FE}=2,287$ & TT & 0 & TT & 0 \\
\hline & 50 & 13.75 & $\begin{array}{l}3953298.2 \\
5\end{array}$ & $\begin{array}{l}\mathrm{TE}=0,888 \\
\mathrm{FRT}=0,197\end{array}$ & TT & 0 & TT & 0 \\
\hline $\begin{array}{l}\text { STdR } \\
\text { G }\end{array}$ & 140 & 19.25 & $\begin{array}{l}65888304 . \\
23\end{array}$ & $\begin{array}{l}\mathrm{FE}=2,451 \\
\mathrm{TE}=0,805 \\
\mathrm{FRT}=0,179\end{array}$ & $\mathrm{TT}$ & 0 & $\mathrm{TT}$ & 0 \\
\hline Total & & & & & $0 \%<$ & $00 \%$ & $0 \%<$ & $0 \%$ \\
\hline
\end{tabular}

Karena setelah dicoba dengan taksiran pelat beton semen $30 \mathrm{~cm}$, menunjukan bahwa persentasi kerusakan akibat fatik dan erosi kurang dari 100\%, sehingga pelat dengan tebal $30 \mathrm{~cm}$ dianggap sudah mencukupi. Langkah selanjutnya adalah perhitungan penulangan untuk perkerasan beton bersambung dengan tulangan.

\begin{tabular}{|c|c|}
\hline Pelat Beton K-375 & \multirow{2}{*}{$30 \mathrm{~cm}$} \\
\hline Campuran Beton Kurus & \\
\hline Tanah Dasar CBR 2,8\% & $125 \mathrm{~mm}$ \\
\hline
\end{tabular}

Gambar 4. Gambar Perkerasan Jalan yang akan digunakan

Perhitungan penulangan akan disajikan dalam perhitungan, berdasarkan data-data berikut :

- Tebal pelat : $30 \mathrm{~cm}$

- Lebar pelat : 2 × 3,5 meter

- Panjang pelat : 15 meter

- $\quad$ Koef. gesek antara pelat dgn pondasi bawah $(\mu)$ $=1,3$

- Kuat tarik ijin baja $\left(\mathrm{f}_{\mathrm{s}}\right) \quad: 240 \mathrm{MPa}$

- Berat ijin beton : $2400 \mathrm{~kg} / \mathrm{m}^{3}$
- Percepatan gravitasi $\quad: 9,81 \mathrm{~m} / \mathrm{dt}^{2}$

\section{Perhitungan tulangan memanjang :}

Luas tulangan memanjang $\left(\mathrm{mm}^{2}\right.$ per lebar pelat dengan $\mathrm{L}=$ panjang pelat).

As $=\frac{\mu \times \mathrm{LxM \times g \times h}}{2 \mathrm{f}_{\mathrm{s}}}$

As $=\frac{1,3 \times 15 \times 2400 \times 9,81 \times 0,3}{2 \times 240}$

As $=286,942 \mathrm{~mm}^{2}$

Luas tulangan memanjang dicek terlebih dahulu berdasarkan luas tulangan minimum ( $\mathrm{A}_{\mathrm{s}}$ minimum).

$\mathrm{A}_{\mathrm{S}}$ minimum $=0,1 \%$ luas penampang beton

$$
\begin{aligned}
& =0,1 \% \times 300 \times 1000 \\
& =300 \mathrm{~mm}^{2} / \mathrm{m}
\end{aligned}
$$

Diambil luas tulangan yang digunakan sebesar 300 $\mathrm{mm}^{2} / \mathrm{m}$. Untuk penulangan digunakan $\varphi 8 \mathrm{~mm}$ dengan jarak $150 \mathrm{~mm}\left(335 \mathrm{~mm}^{2} / \mathrm{m}\right)$.

\section{Perhitungan tulangan melintang :}

Luas tulangan memanjang $\left(\mathrm{mm}^{2}\right.$ per lebar pelat dengan $\mathrm{L}=$ panjang pelat).

$$
\begin{aligned}
\text { As } & =\frac{\mu \times \mathrm{L} \times \mathrm{M} \times \mathrm{g} \times \mathrm{h}}{2 \mathrm{f}_{\mathrm{s}}} \\
\text { As } & =\frac{1,3 \times 7 \times 2400 \times 9,81 \times 0,3}{2 \times 240} \\
\text { As } & =133,906 \mathrm{~mm}^{2}
\end{aligned}
$$

Luas tulangan memanjang dicek terlebih dahulu berdasarkan luas tulangan minimum ( $\mathrm{A}_{\mathrm{s}}$ minimum).

$\mathrm{A}_{\mathrm{s}}$ minimum $=0,1 \%$ luas penampang beton

$$
=0,1 \% \times 300 \times 1000
$$




$$
=300 \mathrm{~mm}^{2} / \mathrm{m}
$$

Diambil luas tulangan yang digunakan sebesar 300 $\mathrm{mm}^{2} / \mathrm{m}$. Untuk penulangan digunakan $\varphi 8 \mathrm{~mm}$ dengan jarak $150 \mathrm{~mm}\left(335 \mathrm{~mm}^{2} / \mathrm{m}\right)$.

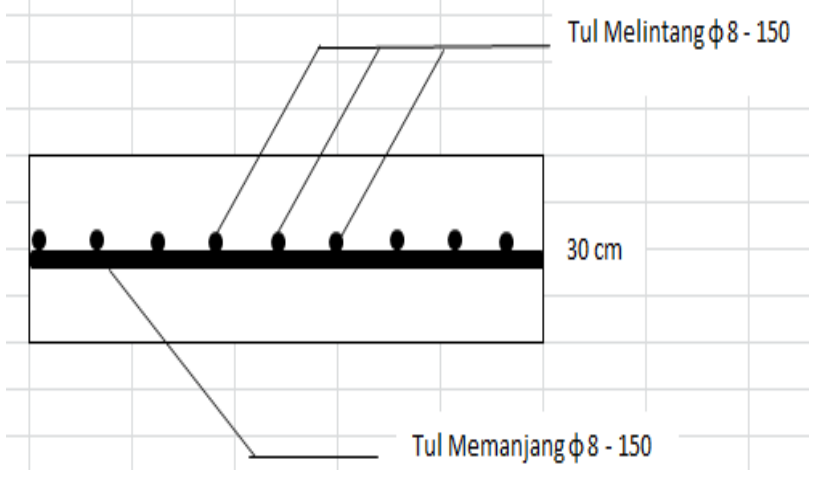

Gambar 5. Gambar Penulangan Melintang dan Memanjang

\section{5. . KESIMPULAN}

Dari pengumpulan data hingga analisa data yang telah dilakukan dalam Penelitian ini, didapatkan beberapa kesimpulan berdasarkan hasil analisa data dan evaluasi perencanaan dalam Penelitian ini, diantaranya :

1. Berdasarkan hasil surver Lalu Lintas Harian pada ruas Jalan Raya Cariu yang telah dilakukan oleh pihak Dinas Bina Marga Provinsi Jawa Barat pada tahun 2014, didapatkan lalu lintas harian rata-rata sebagai berikut :

Tabel 4. Komposisi Tiap Jenis Kendaraan (kend/hari/2 arah)

\begin{tabular}{ll}
\hline \multicolumn{1}{c}{ Jenis Kendaraan } & \multicolumn{1}{c}{$\begin{array}{c}\text { Jumlah } \\
\text { (kend/hari) }\end{array}$} \\
\hline Kendaraan Ringan 2 T (1+1) & 11.034 \\
\hline Bus 2 as 8 T (3+5 G) & 57 \\
\hline Truck 2 as Kecil 6 T (2+4) & 1.614 \\
\hline Truck 2 as Besar 13 T (5+8G) & 966 \\
\hline Truck 3 as 20 T (6+14TdG) & 1.004 \\
\hline Truck Gandengan 20 T dan \\
10 T (6+14TdG+5+5) & 72 \\
\hline Total & 14.747 \\
\hline
\end{tabular}

2. Berdasarkan nilai CBR yang didapat dari perencanaan teknis ruas jalan CimuncangCipinang. didapatkan nilai CBR yang mewakili sebesar 2,8\%. Dari nilai CBR tanah dasar tersebut diperoleh nilai CBR efektif sebesar 28\%, berdasarkan Gambar 3, "Perencanaan Perkerasan Jalan Beton Semen, Pd T-14-2003”, untuk CBR tanah dasar 2,8\%.

3. Tebal pelat beton yang direncanakan setebal 30 $\mathrm{cm}$, dengan jenis dan tebal pondasi bawah adalah campuran beton kurus setebal $125 \mathrm{~mm}$, tebal pondasi bawah tersebut diambil berdasarkan Gambar 2, "Perencanaan Perkerasan Jalan Beton Semen, Pd T-14-2003", untuk CBR tanah dasar $2,8 \%$ dan JSKN 470.630.744,5. Tebal pelat ini lebih besar dari tebal pelat eksisting pada ruas jalan yang dikaji, yaitu setebal $18 \mathrm{~cm}$. Kerusakan jalan yang terjadi pada ruas jalan yang dikaji, mungkin terjadi akibat tebal pelat beton yang kurang dan tidak menggunakan tulangan.

4. Penulangan pelat yang digunakan (dalam kasus ini digunkan pelat beton bersambung dengan tulangan) adalah :

- Tulangan diameter $8 \mathrm{~mm}$ dengan jarak 150 mm untuk tulangan memanjang, dan

- Tulangan diameter $8 \mathrm{~mm}$ dengan jarak 150 mm untuk tulangan melintang.

Nilai jarak tulangan tersebut diambil berdasarkan luas tulangan minimum $\left(\mathrm{A}_{\mathrm{s}}\right.$ minimum).

\section{DAFTAR PUSTAKA}

Ilham, Diktat Kuliah Perencangan Perkerasan Jalan.

Ilham, Diktat Kuliah Rekayasa Transportasi

SNI. 1997. Tata Cara Perencanaan Geometrik Jalan Antar Kota No. 038/TBM/1997. Departemen Pekerjaan Umum Direktorat Jenderal Bina Marga. Jakarta.

SNI. 2003. Perencanaan Perkerasan Jalan Beton Semen Pd T-14-2003. Departemen Permukiman dan Prasarana Wilayah. Jakarta.

Sukirman, Silvia, 1999. Perkerasan Lentur Jalan Raya. Penerbit Nova. Bandung. 